
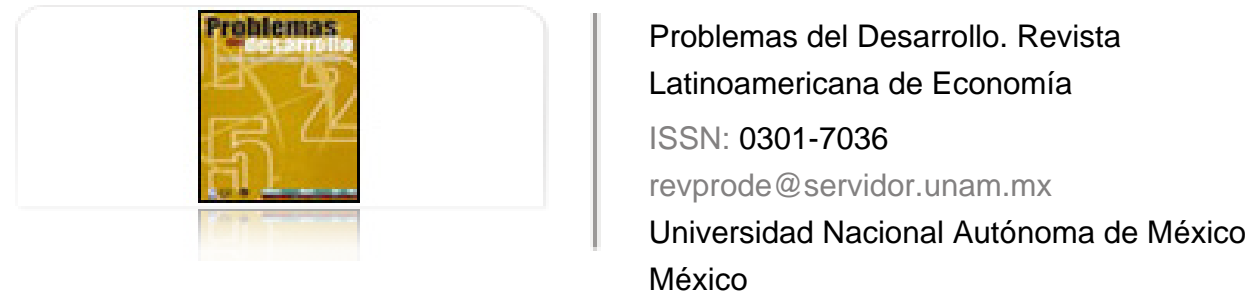

Cuevas Ahumada, Víctor M.; Chávez Gutiérrez, Fernando J.

Déficit, deuda y reforma fiscal en México

Problemas del Desarrollo. Revista Latinoamericana de Economía, vol. 38, núm. 148, enero-marzo, 2007, pp. 69-97

Universidad Nacional Autónoma de México

Distrito Federal, México

Disponible en: http://www.redalyc.org/articulo.oa?id=11820155004

Cómo citar el artículo

- Número completo

- Más información del artículo

Página de la revista en redalyc.org

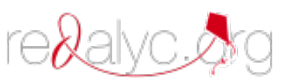

Sistema de Información Científica

Red de Revistas Científicas de América Latina, el Caribe, España y Portugal Proyecto académico sin fines de lucro, desarrollado bajo la iniciativa de acceso abierto 


\section{DÉFICIT, DEUDA Y REFORMA FISCAL EN MÉXICO*}

\section{Víctor M. Cuevas Ahumada** Fernando J. Chávez Gutiérrez ${ }^{* * *}$}

Fecha de recepción: 11 de agosto de 2006. Fecha de aceptación: 7 de noviembre de 2006.

\section{Resumen}

El presente trabajo analiza, a grandes rasgos, la problemática del déficit fiscal y la deuda pública en México, así como la necesidad de realizar una reforma hacendaria que fortalezca la recaudación y amplie la base gravable. En ese contexto, se estudian las principales corrientes teóricas en torno de los efectos del déficit fiscal en la economía, particularmente en variables como la tasa de interés, el tipo de cambio, la actividad económica y los precios. Posteriormente, con base en evidencia empírica obtenida mediante la estimación de un parsimonioso modelo de autorregresión vectorial, se concluye que una reducción transitoria del déficit del sector público surtiría los siguientes efectos de corto plazo en la economía mexicana: caída de las tasas de interés, disminución de las presiones inflacionarias y apreciación del tipo de cambio. Finalmente, se hace una breve reflexión respecto de los principios fundamentales que podrian orientar una reforma fiscal integral en nuestro país.

Palabras clave: déficit fiscal, deuda pública, inflación, reforma hacendaria, economía mexicana.

* Los autores agradecen las observaciones y sugerencias de dos dictaminadores anónimos, pues éstas contribuyeron sustancialmente a mejorar la calidad del trabajo. Los errores y omisiones que pudieran subsistir son, sin embargo, responsabilidad nuestra.

** Profesor investigador del Departamento de Economía de la UAM $\sim$ y miembro del Sistema Nacional de Investigadores. Correo electrónico: victorcuevas@att.net.mx

*** Profesor investigador del Departamento de Economía de la UAM A. Correo electrónico: ferchav50@prodigy.net.mx 
Abstract

This paper analyzes, in broad outline, the problematic of the fiscal deficit and public debt in Mexico, as well as the need to carry out a Treasury reform that will strengthen tax collection and broaden the tax base. In this context, it studies the main theoretical currents regarding the effects of the fiscal deficit on the economy, and particularly on such variables as the rate of interest, the exchange rate, economic activity and prices. Afterwards, based on the empirical evidence obtained by estimating a moderate model of vector self-regression, it is concluded that a transitory reduction in the public sector deficit would have the following short-term effects on Mexico's economy: a fall in interest rates, a reduction in inflationary pressures and an appreciation of the peso. Finally, we reflect briefly on the main fundamentals that could be used to orient an integral fiscal reform in our country.

Key words: fiscal deficit, public debt, inflation, Treasury reform, Mexican economy.

Résumé

Ce travail analyse, dans ses grands traits, la problématique du déficit fiscal et de la dette publique au Mexique, ainsi que le besoin de réaliser une réforme du Trésor public qui affermisse le recouvrement et étende l'assiette des impôts. Dans ce contexte sont étudiés les principaux courants théoriques qui traitent des effets du déficit fiscal dans l'économie, notamment sur des variables comme le taux d'intérêt, le cours du change, l'activité économique et les prix. Ensuite, sur la base de la preuve empirique obtenue par l'estimation d'un modèle parcimonieux d'auto-régression vectorielle, il est conclu qu'une réduction transitoire du déficit du secteur public produirait les effets à court terme suivants sur l'économie mexicaine: chute des taux d'intérêt, diminution des pressions inflationnistes et appréciation du cours du change. Finalement une petite réflexion est menée concernant les principes fondamentaux qui pourraient orienter une réforme intégrale dans notre pays.

Mots clés: déficit fiscal, dette publique, inflation, réforme du Trésor public, économie mexicaine.

\section{Resumo}

O presente trabajo analisa, em grandes linhas, a problemática do déficit fiscal e a dívida pública no México, assim como a necessidade de realizar uma reforma fazendária que fortaleça a arrecadação e amplie a base tributável. Neste contexto, estudam-se as principais correntes teóricas em torno dos efeitos do déficit fiscal na economia, particularmente em variáveis como a taxa de juros, o tipo de câmbio, a atividade econômica e os preços. Posteriormente, com base em evidência empírica obtida mediante a estimação de um parsimonioso modelo de autorregressão vetorial, conclui-se que uma redução transitória do déficit do setor público surtiría os seguintes efeitos de curto prazo na economia mexicana: queda das taxas de juros, diminuição das pressões inflacionárias e apreciação do tipo de câmbio. Finalmente, faz-se uma breve reflexão com respeito a princípios fundamentais que poderiam orientar uma reforma fiscal integral no nosso país.

Palavras chave: déficit fiscal, divida pública, inflação, reforma fazendária, economia mexicana. 


\section{Introducción}

néxico, la reducción del déficit del sector público ha sido un objetivo
permanente de la política económica desde el 1 de diciembre de 1982, cuando
se instrumentó el Programa Inmediato de Reordenación Económica (PIRE). El fundamento teórico de las medidas de saneamiento fiscal impulsadas por el gobierno desde aquel entonces se encuentra en el denominado enfoque fiscal de la inflación. De acuerdo con éste, una de las principales fuentes de inestabilidad en los precios radica, precisamente, en un déficit público persistente y excesivo. En ese contexto, factores como la ineficiencia en la recaudación de impuestos, el escaso desarrollo de los mercados financieros domésticos, la limitada capacidad de endeudamiento gubernamental en el exterior y el bajo costo que entraña el señoriaje en comparación con la contratación de pasivos internos y externos han orillado eventualmente a países en desarrollo, como México, a sobreemitir dinero - y, por ende, a generar inflación - para poder financiar la brecha entre los gastos y los ingresos públicos. ${ }^{1}$

Por supuesto, además de inflación, un déficit fiscal de magnitud considerable engendra una deuda pública creciente. En el caso del endeudamiento interno, las emisiones masivas de instrumentos de deuda gubernamentales en el mercado financiero local presionan las tasas de interés a la alza y disminuyen la oferta doméstica de fondos prestables para el sector privado. En el caso del endeudamiento externo, tanto la solicitud de créditos a organismos financieros multilaterales y bancos transnacionales, como la colocación de bonos globales en mercados financieros foráneos pueden generar escasez de divisas en situaciones límite, crisis en el sector externo de la economía y macroajustes cambiarios. Asimismo, el déficit y la deuda consolidada del gobierno pueden conducir no sólo a problemas de liquidez y de solvencia, sino a incrementos en los impuestos que desincentiven el consumo, la inversión privada y el crecimiento económico en el largo plazo.

1 Rogers y Wang (1994) aportan evidencia empírica consistente con el enfoque fiscal de la inflación en el caso particular de México durante el periodo 1977 1990. Podría decirse que los pioneros de ese enfoque son Sargent y Wallace (1981), mientras que Alesina y Drazen (1991) y Calvo y Végh (1999) son algunos de sus más notables seguidores. 
La finalidad del presente trabajo consiste en analizar a grandes rasgos la problemática fiscal del país, la necesidad de una reforma hacendaria que fortalezca la recaudación y amplíe la base gravable, y los efectos de una caída en el déficit público sobre las tasas de interés, el tipo de cambio, la inflación y el crecimiento económico. Adicionalmente, se hace una reflexión acerca de los principios fundamentales que podrían orientar una reforma del sistema hacendario en nuestro país.

El presente artículo se divide en cuatro secciones. La primera analiza los efectos del déficit fiscal en la economía, con base en un sucinto análisis de la literatura reciente. La segunda examina algunos indicadores importantes en torno del déficit fiscal y la deuda pública en México. La tercera recurre tanto a la teoría como al análisis empírico para intentar visualizar las repercusiones básicas, principalmente de corto plazo, que tendría una reforma fiscal que redujera el déficit del sector público. La cuarta sección versa acerca de los criterios generales que podrían orientar una eventual reforma fiscal en México. Finalmente, se hace la presentación de las conclusiones.

\section{Déficit fiscal, tasas de interés y crecimiento económico: una breve revisión de la literatura reciente}

Las corrientes teóricas sobre los efectos del déficit fiscal en la economía son esencialmente cuatro: $a$ ) la keynesiana; $b$ ) la de la equivalencia ricardiana; $c$ ) la tradicional; $d$ ) la del riesgo país. ${ }^{2}$ En esencia, la teoría keynesiana establece que una política fiscal expansiva alimenta la demanda agregada y estimula, por esa vía, el crecimiento de la economía. En el modelo keynesiano estático, con precios inflexibles y márgenes amplios de capacidad instalada ociosa, la producción aumenta de manera considerable sin que la inflación se dispare. ${ }^{3}$ Algunos estudios recientes, como los de Sutherland (1997) y Perotti (1999), señalan que la política fiscal surte efectos positivos en la actividad económica solamente cuando la deuda gubernamental se ubica en niveles relativamente bajos. ${ }^{4}$ En una investigación empírica más recien-

2 Con excepción de la teoría de la equivalencia ricardiana, que es una teoría de largo plazo, todas las teorías aquí presentadas se refieren a los efectos del déficit fiscal en horizontes de corto plazo.

3 Estos efectos pueden variar dependiendo de los supuestos que se formulen en torno del grado de rigidez de los precios, el coeficiente de apertura de la economía, la capacidad productiva excedente, el comportamiento de las tasas de interés y el régimen cambiario vigente.

4 Si la deuda pública es excesiva, una política fiscal expansiva puede generar efectos recesivos en la economía. Ello en virtud de que los agentes económicos pueden poner en tela de juicio 
te, basada en el comportamiento de cinco economías de la OCDE, el propio Perotti (2002) concluye que los efectos del déficit fiscal en el PIB se han tornado demasiado tenues en las últimas dos décadas.

De acuerdo con la teoría de la equivalencia ricardiana (ER), encabezada por autores como Barro (1974), Plosser (1982, 1987) y Evans (1985, 1987a, 1987b), un aumento o disminución del déficit fiscal no surte efecto alguno sobre las tasas de interés ni sobre el crecimiento de la economía. La explicación de ello radica en que los agentes económicos saben que una política fiscal expansiva desemboca en una mayor deuda pública y, eventualmente, en incrementos impositivos para hacer frente a los crecientes pasivos del gobierno. La expectativa de impuestos más elevados (derivados del crecimiento en el déficit fiscal) provoca que los individuos ahorren más, dado que un mayor ahorro les permitirá conservar sus niveles de bienestar cuando las tasas impositivas se ajusten. De esa manera, los autores referidos postulan que el ahorro doméstico privado (u oferta de crédito) aumenta en la misma medida que el déficit fiscal (o demanda de crédito), por lo cual las tasas de interés, la inversión doméstica privada y el crecimiento de la economía permanecen sin cambios en el largo plazo. ${ }^{5}$

Por otra parte, la llamada teoría tradicional, señala que una expansión del déficit fiscal eleva tanto los precios como las tasas de interés ${ }^{6}$ y desincentiva, por ese medio, el crecimiento de la economía. Asimismo, al aumentar los rendimientos en moneda doméstica se propicia una mayor entrada de inversión extranjera de cartera y una apreciación del tipo de cambio. ${ }^{7}$ Una contracción del déficit fiscal, contrariamente,

la solvencia gubernamental, formándose de ese modo expectativas de mayores impuestos y mayor inflación. Tales expectativas, aunadas al debilitamiento de la confianza de productores y consumidores, tienden a elevar las tasas de interés a largo plazo y a desalentar, por tanto, el consumo de bienes duraderos, la inversión productiva y la actividad económica.

5 La evidencia empírica relacionada con la teoría de la ER es mixta. Entre las investigaciones empíricas que cuestionan su validez, pueden citarse: Ball y Mankiw (1995) y Doménech, Taguas y Varela (2000). Asimismo, en el terreno teórico, Stiglitz (1988) demuestra que la ER únicamente puede validarse con supuestos muy estrictos y, hasta cierto punto, irreales. Ello, sin embargo, no ha impedido que algunos autores, como Bayoumi y Masson (1998) y De Mello et al. (2004), aporten evidencia empírica en favor de dicha teoría. Existen incluso trabajos, como el de Giorgioni y Holden (2003), que obtienen evidencia consistente con la ER en el caso de algunos países en desarrollo.

6 Si el déficit fiscal se financia - total o parcialmente - mediante una colocación masiva de bonos gubernamentales, entonces la demanda de fondos prestables a cargo del sector público se incrementa y ello, a su vez, provoca mayores tasas reales de interés.

7 Es pertinente señalar que, bajo determinados supuestos (tales como economía abierta, precios relativamente flexibles, escasos márgenes de capacidad instalada ociosa, tasas de interés 
favorece que las tasas de interés caigan y que la economía crezca, al tiempo que induce salidas (o menores entradas) de capital y depreciaciones monetarias. Es procedente señalar que la corriente teórica tradicional proviene de la versión moderna del modelo de Mundell y Fleming (1987), que supone la existencia de una economía pequeña o mediana, con libre movilidad de capital y tipo de cambio flexible. Entre los trabajos recientes que suscriben esa corriente de pensamiento se pueden listar los siguientes: Blanchard (1981, 1984, 1985), Blanchard y Dornbusch (1984), Branson, Fraga y Johnson (1985), Dornbusch (1986), Feldstein (1984) y Reinhart y Sack (2000:175).

La cuarta corriente teórica incorpora la variable riesgo país en el análisis, por lo cual podría llamársele teoría del riesgo país de la política fiscal. Esa vertiente de pensamiento establece que un mayor déficit fiscal, aun cuando efectivamente presiona las tasas de interés a la alza y el nivel de actividad económica a la baja, no induce una apreciación, sino una depreciación de la moneda doméstica. La razón de esa aparente paradoja es que el déficit fiscal constituye uno de los llamados fundamentos de la economía y es objeto de monitoreo constante por parte de las calificadoras de valores internacionales y de los inversionistas en general. En esa tesitura, una ampliación importante del déficit fiscal, con la condición ceteris paribus, acrecienta las expectativas de inflación y el riesgo país, merma la confianza de los inversionistas, disminuye eventualmente la calificación (o su perspectiva) de riesgo soberano otorgada por las calificadoras referidas, provoca salidas masivas de capital y deprecia la moneda doméstica. ${ }^{8}$ Inversamente, una contracción significativa del déficit del sector público, si bien reduce las tasas de interés e incentiva la actividad económica, no desemboca en una depreciación, sino en una apreciación cambiaria. Ello obedece a que el menor déficit fortalece la confianza de los inversionistas, mejora eventualmente la calificación de riesgo crediticio del país en cuestión y se traduce en mayor atracción de capital foráneo. Entre los partidarios de esa teoría se encuentran McDermott y Wescott (1996), Eichengreen (2000:67) y Cuevas (2002). En el caso concreto de México, Cuevas (2002) demuestra empírica-

determinadas por la oferta y la demanda de fondos prestables y tipo de cambio flexible), los efectos del déficit fiscal en la economía podrían ser esencialmente los mismos para las corrientes keynesiana y tradicional. En ese contexto, hay que admitir que resulta difícil establecer una frontera nítida entre esas dos escuelas.

8 De esa manera, las salidas de capital y las depreciaciones cambiarias sobrevendrían a pesar de los mayores rendimientos reales pagados por las inversiones en moneda doméstica, concretamente, por los instrumentos de deuda. 
mente que una política fiscal expansionista eleva las tasas de interés y el nivel de precios, reduce el crecimiento de la economía y deprecia la moneda doméstica en el corto plazo.

Finalmente, Botman y Kumar (2006), al utilizar un modelo de equilibrio general sólidamente microfundamentado, aportan evidencia (tanto teórica como empírica) en el sentido de que los efectos de la política fiscal en la economía dependen del horizonte de planeación de los consumidores, del acceso de los agentes económicos a los mercados financieros, de la elasticidad de la oferta laboral y de las estructuras de mercado existentes, entre otros factores.

\section{Déficit fiscal y deuda pública: una mirada a los datos}

Con la finalidad de estabilizar los precios y las tasas de interés, crear condiciones más propicias para que la economía crezca y revertir la tendencia de crecimiento de la deuda pública, el gobierno federal se ha venido empeñando en cerrar gradualmente la brecha entre el gasto y los ingresos públicos. En la Gráfica 1 se resumen los frutos de ese esfuerzo permanente, puesto que a partir de 1999 tanto el déficit del sector público, como los Requerimientos Financieros del Sector Público (RFSP, en lo sucesivo) exhiben una marcada propensión a la baja.

El esfuerzo de saneamiento fiscal referido, como puede constatarse en la Gráfica 2, ha permitido que la deuda pública neta total descienda de manera sostenida — como porcentaje del PIB — a partir de mediados de la década de los noventa. Sin embargo, entre la deuda pública y el denominado Saldo Histórico de los Requerimientos Financieros del Sector Público (SHRFSP) se ha venido abriendo un abismo que pone en riesgo la solvencia fiscal del Estado en el largo plazo. ${ }^{9}$

Es importante precisar que, en 2005, el déficit público y los RFSP representaron 0.2 y $1.7 \%$ del PIB del país, respectivamente. Asimismo, en el año referido, la deuda pública y el SHRFSP alcanzaron una magnitud equivalente a 21.9 y $37.5 \%$ del PIB, respectivamente. Y aun cuando esas cifras no parecen elevadas en comparación

$9 \quad$ El SHRFSP es igual a la deuda pública oficialmente reconocida más los pasivos implícitos del sector público, mismos que incluyen a los pasivos netos del IPAB, las deudas del Fideicomiso de Apoyo al Rescate Carretero (FARAC), los PIDIREGAS, las obligaciones de la Banca de Desarrollo y de los diferentes fondos y fideicomisos públicos para el fomento económico, y el programa de apoyo a deudores de la banca. Los RFSP, por su parte, además de incluir al déficit público tradicional, consideran las erogaciones destinadas a cubrir el servicio de los pasivos del IPAB y el FARAC, así como el pago de los intereses correspondientes al resto de las obligaciones extraoficiales del gobierno. 


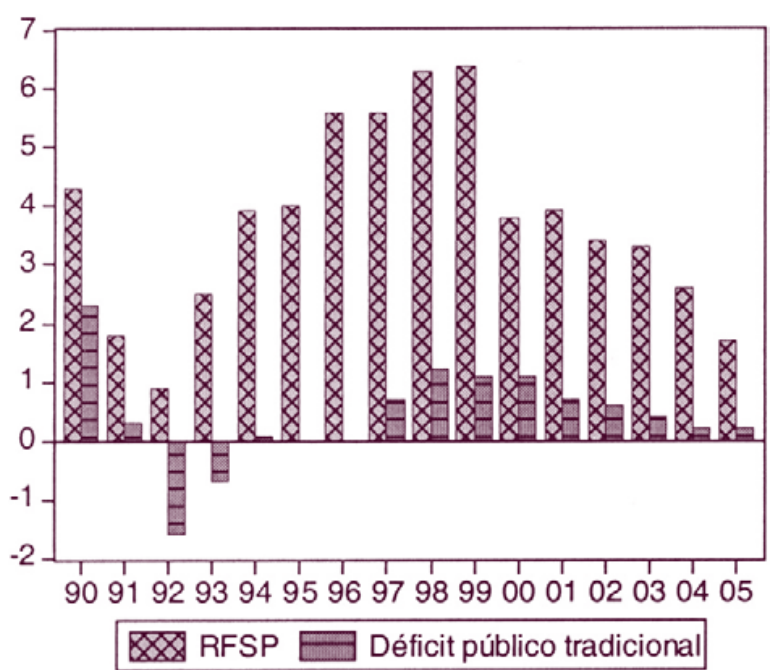

Gráfica 1. Déficit público (+) y RFSP (\% del PIB).*

Nota: en 1992 y 1993 se registró un superávit público, mientras que en 1995 y 1996 el presupuesto fue equilibrado.

* Sin considerar ingresos extraordinarios.

Fuente: SHCP.

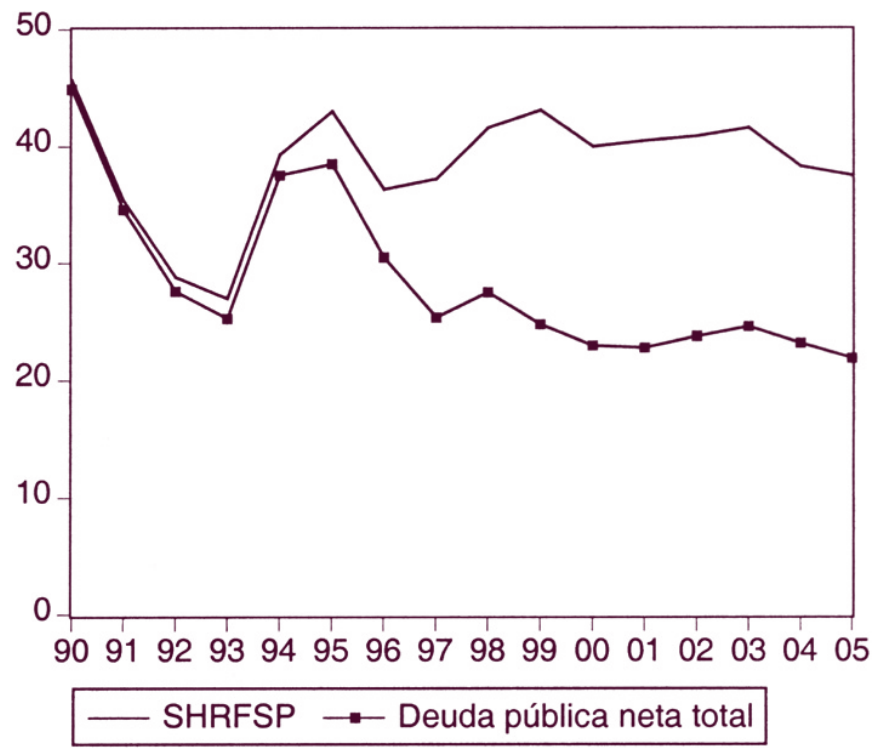

Gráfica 2. Deuda pública y SHRFSP (\% del PIB).

Fuente: SHCP. 


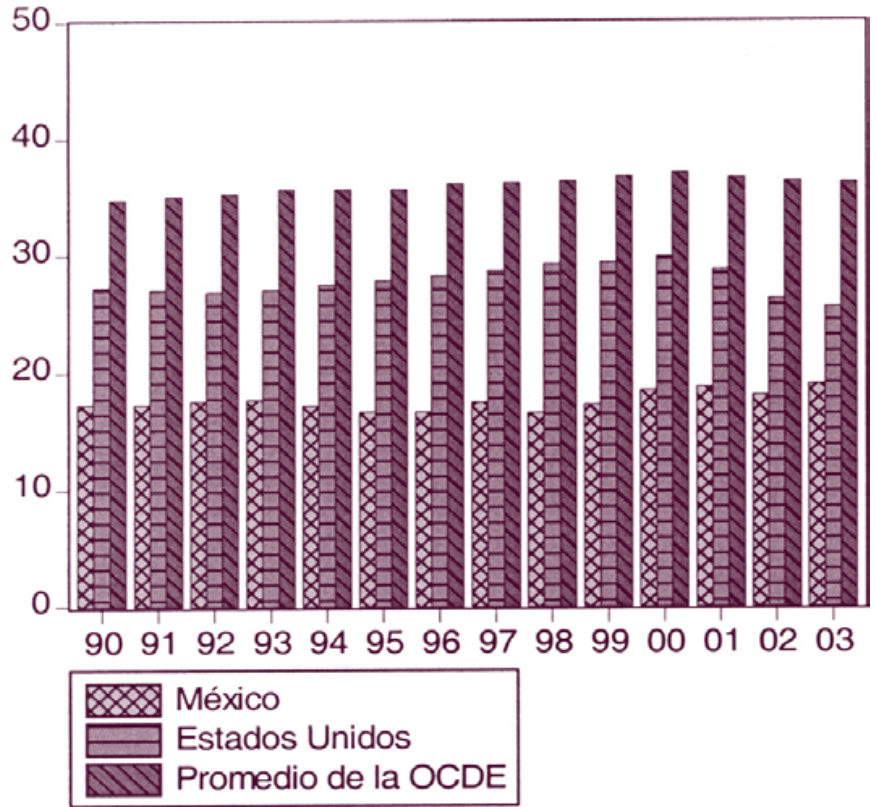

Gráfica 3. Recaudación fiscal en México y otros países (\% del PIB). Fuente: OCDE.

con los estándares de la OCDE, ${ }^{10}$ existen por lo menos tres problemáticas generales a las cuales habría que prestar atención en el mediano y largo plazos: la baja recaudación fiscal, el grado de petrolización de los ingresos públicos y las obligaciones contingentes del gobierno. La exigua recaudación fiscal que prevalece en México es un indicador clave del estrecho margen de maniobra que el gobierno tiene para enfrentar sus pasivos explícitos e implícitos, reales y contingentes. La Gráfica 3 evidencia que, en el terreno del esfuerzo fiscal, medido a través de la participación de los ingresos públicos en el PIB, el gobierno de México se encuentra muy a la zaga de Estados Unidos y de otras naciones de la OCDE. Además, habría que considerar la elevada dependencia del fisco respecto de los ingresos provenientes de las exportaciones de petróleo (véase la Gráfica 4).

Como puede observarse, en 2005 los ingresos petroleros representaron $34.7 \%$ de los ingresos totales del gobierno federal. Asimismo, en el periodo 2000-2004 los ingresos petroleros promediaron alrededor de $28 \%$ de la recaudación total, lo cual

10 Las naciones de la OCDE, excluyendo a México, promediaron un déficit público de $3.2 \%$ del PIB al cierre de 2005. Por otro lado, la deuda pública neta total de los países de dicha organización reportó, en promedio, una cifra equivalente a $46.5 \%$ del PIB en el mismo año (Fuente: OCDE). 


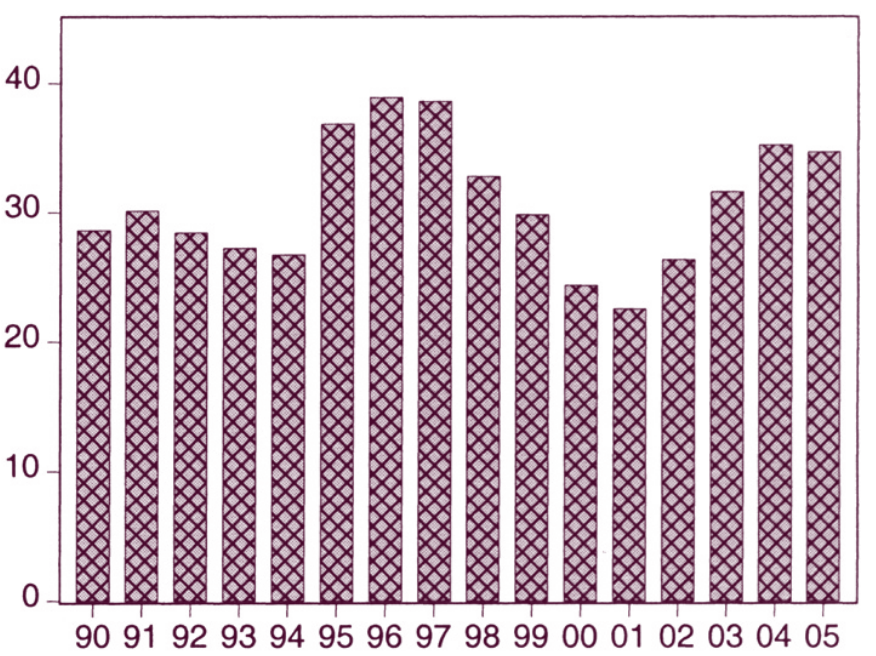

Ingresos petroleros

Gráfica 4. Participación porcentual de los ingresos petroleros en los ingresos totales del gobierno federal. Nota: el cálculo incluye rendimientos extraordinarios provenientes de la venta de empresas, así como derechos por hidrocarburos y aprovechamientos sobre rendimientos excedentes.

Fuente: elaboración propia con base en datos de la SHCP.

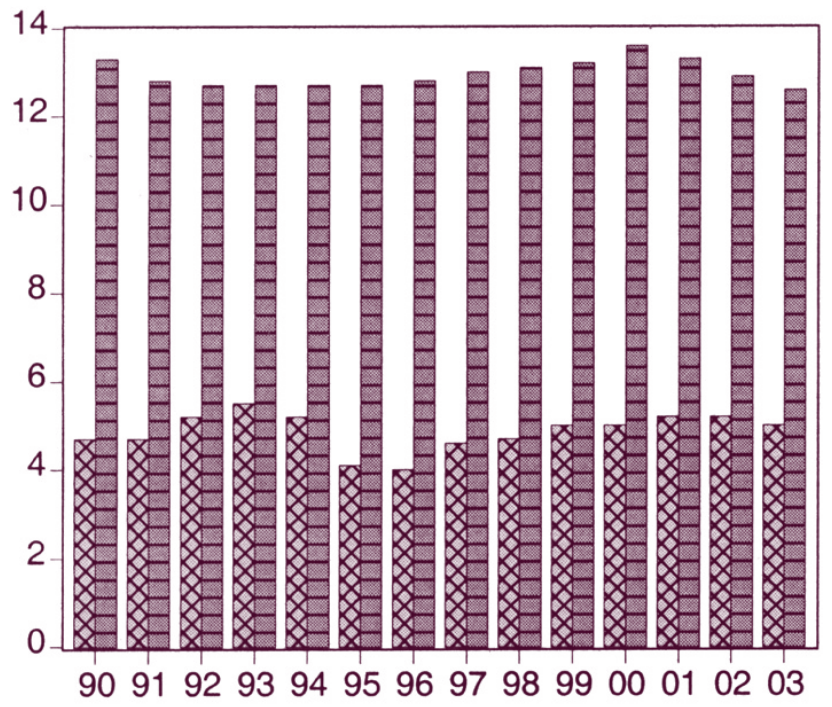

México Promedio de la OCDE

Gráfica 5. Recaudación de impuesto sobre la renta en México y otros países (\% del PIB). Fuente: OCDE. 
brinda una panorámica del nivel de exposición de las finanzas públicas frente a variaciones inesperadas en los precios internacionales del petróleo. Desde luego, el Fondo de Estabilización Petrolera constituye un paliativo importante al respecto, puesto que ha servido para amortiguar los impactos derivados de los altibajos en el mercado internacional del crudo. Dicho fondo, sin embargo, debe complementarse con una reforma fiscal integral (RFI) que amplíe la base gravable y fortalezca los ingresos tributarios no petroleros. Al ampliarse y diversificarse la base gravable, los ingresos presupuestarios totales serían no sólo más elevados sino, también, más estables y predecibles.

La Gráfica 5 sugiere que el rezago de México en materia de recaudación tributaria obedece, en buena medida, a la escasa participación del impuesto sobre la renta (ISR) - tanto de las personas físicas como de las morales- en el PIB del país. Así pues, se aprecia que la brecha entre la carga de ISR en México y en el resto de las naciones de la OCDE es significativa, lo cual refleja de manera elocuente la necesidad de combatir frontalmente la informalidad y la evasión fiscal, así como de poner fin a regímenes de exención injustificados, con el objeto de que más personas, unidades productivas e industrias aporten lo que realmente les corresponde al fisco. Hay que reconocer, sin embargo, que una mayor recaudación de impuestos directos tendría no sólo ventajas sino, también, desventajas potenciales, las cuales habría que considerar. Por una parte, ayudaría a corregir el acentuado desfase de México en el renglón aludido, fortalecería la posición fiscal del Estado y acrecentaría la equidad del sistema impositivo. Por otra parte, podría ir en detrimento de la eficiencia en la asignación de recursos, del ahorro y de la creación de fuentes de trabajo (véanse pp. 35-39).

La Gráfica 6 revela, asimismo, una relación directa entre la recaudación del ISR (como porcentaje del PIB) y el PIB per capita anual de las naciones de la OCDE. Es importante resaltar, por un lado, que el PIB per capita anual es utilizado como variable proxy del desarrollo económico y, por el otro, que la relación entre el PIB por habitante y la carga de ISR resulta estadísticamente significativa a un nivel de significancia de $1 \% .^{11}$

La solidez de las finanzas del sector público depende igualmente de la estructura de la deuda pública por moneda de denominación, es decir, del tamaño de la deuda pública externa, tanto en términos absolutos como relativos. Ese factor de

11 Esto, con independencia de que el PIB per capita aparezca como la variable explicativa - lo cual parecería más plausible- en la ecuación de regresión o como la variable explicada. 


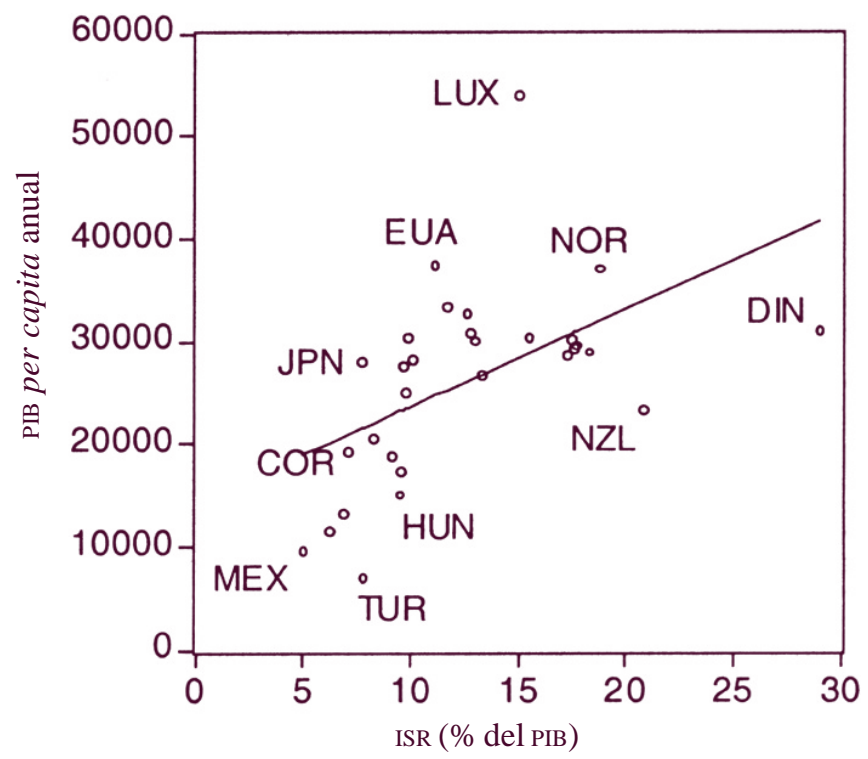

Gráfica 6. PIB per capita anual y carga de ISR en la OCDE, 2003.

Nota: en el cálculo del ingreso per capita se utilizaron precios y paridades corrientes del poder de compra. Fuente: OCDE.

riesgo ha venido diluyéndose gracias a la adecuada gestión de los pasivos externos, a la reiterada imposición de techos anuales, al endeudamiento externo neto del gobierno federal por parte del Congreso de la Unión, y a la sostenida acumulación de reservas internacionales por parte del Banco Central. De hecho, en la Gráfica 7 se constata que la deuda foránea del sector público ha venido decreciendo desde mediados de la década pasada y, a partir de 2001, se ubica incluso por debajo de la deuda doméstica. También se observa que la deuda interna ha venido acrecentando su participación en el PIB, lo cual refleja la estrategia del gobierno federal de financiarse crecientemente en el mercado financiero doméstico. ${ }^{12}$ La Gráfica 8 reporta, por otra parte, que se ha recurrido cada vez en mayor medida a la colocación de instrumentos de deuda a largo plazo, en particular de Bondes y bonos a tasa nominal fija. ${ }^{13}$ En este contexto, caracterizado por la declinación de los pasivos externos

12 Al parecer, el mercado financiero nacional ha podido absorber las colocaciones de valores gubernamentales sin llegar a saturarse, por lo cual no se han disparado las tasas de interés ni se ha provocado un problema grave de escasez de crédito para el sector privado.

13 De allí que el plazo promedio de vencimiento de los valores gubernamentales se haya venido ampliando, de 552 días en enero de 2000 a 1355 días en abril de 2006 (Fuente: Banco de México). 


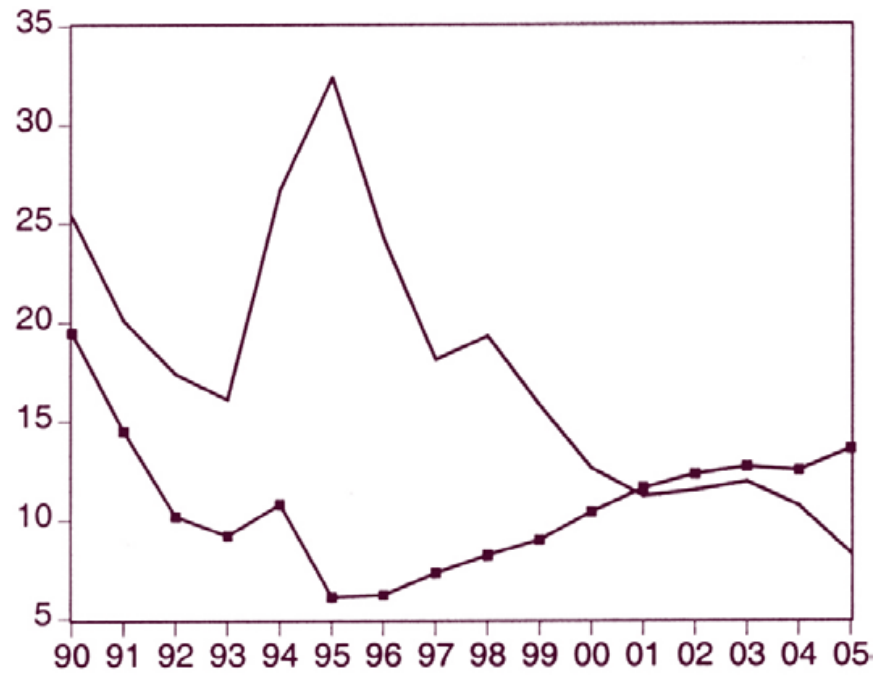

Deuda externa $\rightarrow$ Deuda interna

Gráfica 7. Deuda pública externa e interna netas (\% del PIB). Fuente: SHCP.

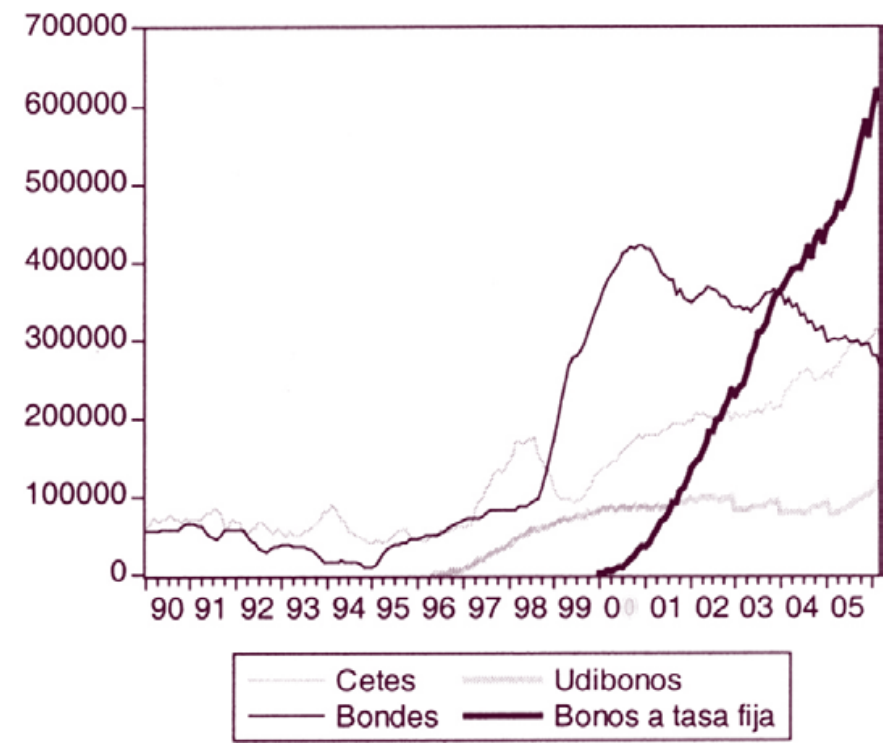

Gráfica 8. Circulación de la deuda interna del sector público por tipo de instrumento.. Nota: miles de millones de pesos a precios corrientes.

Fuente: Banco de México, Indicadores Económicos. 
y por la mayor contratación de deuda interna a tasa fija, es que se ha venido abatiendo el grado de exposición de las cuentas públicas frente a variaciones en las tasas de interés, tanto domésticas como foráneas.

No obstante los logros señalados, es recomendable que se continúe reduciendo tanto la deuda pública como el SHRFSP, habida cuenta que las llamadas obligaciones contingentes, a las cuales nos referimos al inicio de esta sección, podrían eventualmente devenir en una carga insostenible para el Estado mexicano. Vale precisar que las obligaciones contingentes forman parte de las obligaciones implícitas del sector público, pero no se encuentran incluidas en el SHRFSP debido a su marcada naturaleza aleatoria y a la imposibilidad de cuantificarlas. ${ }^{14} \mathrm{El}$ primer componente de la aleatoriedad referida consiste en que tales obligaciones pueden hacerse efectivas o no, dependiendo de la ocurrencia de determinados eventos (por ejemplo, una crisis del sistema bancario que orillara al gobierno a cubrir parte del rescate). El segundo componente de aleatoriedad reside en que, aun cuando pueda preverse la eventual materialización de ciertas obligaciones, persista un amplio grado de incertidumbre sobre el momento en que ello podría ocurrir e, incluso, sobre la cuantía de las erogaciones que habría que realizar. Algunos ejemplos destacados de las obligaciones contingentes del país serían el esquema de seguro de depósito bancario (que se ha venido reformando y mejorando gradualmente), el sistema de pensiones del ISSSTE (cuya reforma es impostergable, puesto que ya depende en niveles muy críticos de transferencias gubernamentales para subsistir), las garantías públicas para la realización de inversiones privadas y el deterioro paulatino de la infraestructura pública y social del país. La existencia de ese tipo de obligaciones, así como las demás preocupaciones planteadas, hacen que las estadísticas de deuda pública y déficit fiscal no sean indicadores precisos sobre el estado actual de las cuentas públicas ni sobre las presiones financieras que podrían sobrevenir en los años venideros. Eso subraya la importancia de emprender una RFI, que no sólo salvaguarde la solvencia del sector público en el largo plazo, sino que permita reivindicar principios fundamentales como la equidad, la eficiencia y la transparencia fiscal. ${ }^{15}$

14 En ese marco, como se ha visto, el sHrFsP incluye solamente la deuda pública y a aquellos pa sivos implícitos que ya se han hecho efectivos y que, por ende, son de carácter no contingente.

15 El 6 de abril de 2006 entró en vigor la Ley Federal de Presupuesto y Responsabilidad Hacendaria, que aspira a establecer como norma constitucional la doctrina económica del equilibrio fiscal. Esa ley abrogó a la Ley de Presupuesto, Contabilidad y Gasto Público, y con ella se reforman muchos procedimientos relacionados con el manejo de las finanzas públicas federales. La nueva normatividad hacendaria, desde nuestro punto de vista, le da un marco jurídico distinto a las relaciones entre el Ejecutivo y el Congreso, que no necesariamente 


\section{¿Qué podría esperarse, en términos generales, de una reforma fiscal que redujera el déficit del sector público y los RFSP?}

Por supuesto, para anticipar las repercusiones económicas de una reforma fiscal cabría analizar las características fundamentales de la misma. Por ejemplo, habría que evaluar los efectos del nuevo sistema impositivo en el consumo de las familias con diferentes niveles de ingreso, en los incentivos para invertir de las micro, pequeñas, medianas y grandes empresas, y en el sistema de estímulos para ahorrar, trabajar y realizar otras actividades. Habría que analizar también los cambios en la magnitud y composición del gasto público, la naturaleza temporal o permanente de algunas medidas en materia de impuestos y de gasto gubernamental, las expectativas de los agentes económicos con relación a futuras iniciativas fiscales y el papel de la política monetaria.

Asimismo, cabría considerar que las variables fiscales constituyen solamente una porción de los fundamentos económicos, institucionales y políticos de un país, y que la capacidad de la economía para crecer, mantener la estabilidad macroeconómica y responder a choques internos o externos depende de una amplia variedad de factores. Sin embargo, este trabajo constituye una primera aproximación al problema planteado, por lo cual se limita a estudiar los efectos básicos que, en el corto plazo, una reducción del déficit público tendría sobre las tasas de interés, el tipo de cambio, los precios y la producción.

\section{Fundamento teórico}

Como habrá de observarse, la evidencia empírica aquí presentada es más bien consistente con el enfoque del riesgo país. Dicho de otro modo, lo que se observa en la parte de análisis empírico es que una compactación del déficit produce los siguientes efectos en el corto plazo: 1) reducción de la tasa de interés; 2) apreciación de la moneda doméstica; 3) descenso de la inflación. ${ }^{16}$

facilitará la revisión y aprobación del gasto público federal anual. A partir del ejercicio fiscal de 2007, consideramos que la nueva ley se pondrá realmente a prueba, pues hay y habrá muchas interrogantes sobre su eficacia y pertinencia jurídica y económica.

16 Por cierto, en la experiencia mexicana reciente se observa una trayectoria de reducción del déficit público, combinada con una apreciación de la moneda doméstica, lo cual contradice a la teoría tradicional y refuerza a la teoría del riesgo país. 
La explicación de la baja en la tasa de interés radica en que, en equilibrio, ésta se encuentra determinada por la interacción entre la oferta y la demanda de fondos prestables. Para ser más precisos, la oferta de fondos prestables se encuentra representada por la suma del ahorro doméstico privado $\left(\mathrm{S}_{\mathrm{P}}\right)$ y el ahorro foráneo $\left(\mathrm{S}_{\mathrm{E}}\right) \cdot{ }^{17}$ La demanda de fondos prestables, por otro lado, es igual a la suma de la inversión doméstica privada (I) y el déficit del sector público (DP). La ecuación (1) formaliza este planteamiento: ${ }^{18}$

$$
\mathrm{S}_{\mathrm{P}}+\mathrm{S}_{\mathrm{E}}=\mathrm{I}+\mathrm{DP}
$$

Como es bien sabido, una importante fuente de financiamiento del déficit público (DP) es la colocación masiva de instrumentos de deuda gubernamentales, tanto de corto como de largo plazo. De esa manera, una contracción del déficit del sector público, acompañada de una menor colocación de instrumentos de deuda del gobierno, moderará la demanda de crédito y permitirá que la tasa de interés de equilibrio descienda. Para la teoría del riesgo país, un abatimiento del déficit fiscal conduce a una apreciación de la moneda doméstica. El mecanismo de transmisión en este caso sería el siguiente:

Reducción del déficit del sector público $\Rightarrow$ fortalecimiento de los fundamentos económicos del país $\Rightarrow$ disminución del riesgo país $\Rightarrow$ robustecimiento de la confianza de los inversionistas foráneos y recorte en la prima por riesgo país $\Rightarrow$ menor riesgo de los instrumentos de deuda denominados en pesos $\Rightarrow$ mejora en la relación riesgorendimiento esperado de los instrumentos de deuda en pesos frente a los instrumentos de deuda en dólares $\Rightarrow$ mayores entradas netas de capital $\Rightarrow$ abundancia relativa de dólares y escasez relativa de pesos $\Rightarrow$ apreciación del peso frente al dólar. ${ }^{19}$

17 El ahorro foráneo o externo, a su vez, es igual a las entradas netas de capital.

18 La ecuación (1) proviene de la identidad del ingreso nacional: $\mathrm{Y}=\mathrm{C}+\mathrm{I}+\mathrm{G}+(\mathrm{X}-\mathrm{M})$. La derivación respectiva puede hacerse en unos cuantos pasos. Primero, se pasa el consumo (C) y el gasto gubernamental (G) del otro lado de la ecuación: $Y-C-G=I+(X-M)$. Segundo, se incorporan los impuestos $(\mathrm{T})$ de la siguiente manera: $(\mathrm{Y}-\mathrm{T})-\mathrm{C}-(\mathrm{G}-\mathrm{T})=\mathrm{I}+(\mathrm{X}-\mathrm{M})$. Tercero, se simplifica la expresión, considerando que $(\mathrm{Y}-\mathrm{T})-\mathrm{C}=\mathrm{S}_{\mathrm{P}} \mathrm{y}$ que $(\mathrm{G}-\mathrm{T})=\mathrm{DP}$, ha ciendo por supuesto abstracción de otras fuentes de ingreso para el gobierno. Este ejercicio conduce a la ecuación: $S_{\mathrm{P}}-\mathrm{DP}=\mathrm{I}+(\mathrm{X}-\mathrm{M})$, o bien, $\mathrm{S}_{\mathrm{P}}-(\mathrm{X}-\mathrm{M})=\mathrm{I}+\mathrm{DP}$. Cuarto, se asume por simplicidad que las exportaciones netas de bienes y servicios $(\mathrm{X}-\mathrm{M})$ son iguales al saldo de la cuenta corriente (que aquí se denotará como CA) y se obtiene la expresión: $\mathrm{S}_{\mathrm{P}}-\mathrm{CA}=\mathrm{I}+\mathrm{DP}$. Finalmente, en virtud de que un déficit en cuenta corriente $(\mathrm{CA}<0)$ como el que registra México constituye una medida del ahorro externo $\left(\mathrm{S}_{\mathrm{E}}\right)$ utilizado por la economía del país en un determinado periodo, se hace la siguiente sustitución: $\mathrm{S}_{\mathrm{P}}+\mathrm{S}_{\mathrm{E}}=\mathrm{I}+\mathrm{DP}$, donde $\mathrm{S}_{\mathrm{E}}=-\mathrm{CA}>0$.

19 El significado del símbolo $\Rightarrow$ es implica. 
No obstante que los enfoques tradicional y el de riesgo país coinciden en lo relativo a los efectos del déficit fiscal sobre las tasas de interés, difieren en lo concerniente a las repercusiones cambiarias. Para la escuela tradicional, una mejora de la situación fiscal redundaría en una depreciación monetaria. El mecanismo de transmisión que llevaría de un menor déficit a un debilitamiento del peso frente al dólar se esboza a continuación:

Reducción del déficit del sector público $\Rightarrow$ descenso en la demanda de crédito $\Rightarrow$ caída de las tasas de interés domésticas $\Rightarrow$ disminución de la rentabilidad de los instrumentos de deuda denominados en pesos versus los instrumentos de deuda denominados en dólares $\Rightarrow$ menores entradas netas de capital $\Rightarrow$ escasez relativa de dólares y abundancia relativa de pesos $\Rightarrow$ depreciación del peso frente al dólar.

En conclusión, para la teoría tradicional, una reforma fiscal que redujera el déficit depreciaría la moneda por medio del descenso en los rendimientos, mientras que para la teoría del riesgo país la susodicha reforma apreciaría la moneda por la vía del aumento en la confianza de los inversionistas (o bien, por la vía del decremento en la percepción de riesgo). El sustento relativo de ambas teorías se verifica al considerar que las decisiones de los inversionistas se basan no solamente en los rendimientos esperados de una alternativa de inversión determinada, sino también, en la ponderación del riesgo que le es inherente. La Condición Ampliada de la Paridad del Interés (CAPI, en lo sucesivo) ilustra esta idea, sugiriendo además que la atracción de capital foráneo exige que la tasa de interés en México iguale o supere a la sumatoria de la tasa de interés estadounidense, la expectativa de ganancia o pérdida cambiaria asociada a las inversiones en dólares y la prima por riesgo país. Si se asume que las opciones de inversión son los CETES a plazo de un año, para el caso de México, y los Bonos del Tesoro Estadounidense (BTE) a un año, para el caso de ese país, entonces se tendrán dos activos financieros estrictamente comparables y la CAPI se formalizaría como sigue:

$$
\mathrm{i}_{\text {CETES }}=\mathrm{i}_{\text {BTE }}+\mathrm{f}+\gamma
$$

en la cual: $\mathrm{i}_{\text {CETES }}=$ tasa de rendimiento de los CETES a un año; $\mathrm{i}_{\text {BTE }}=$ tasa de rendimiento de los BTN a un año; $\mathrm{f}=$ tasa anual de depreciación o apreciación esperada del peso frente al dólar; y $\gamma=$ prima por riesgo país. ${ }^{20}$ Es fácil percatarse de que el

20 Los hermanos Rivera -Batiz (1994:104 105) derivan una ecuación similar a la (2). Aquí lo que procede es, primero, establecer que $\left(1+\mathrm{i}_{\text {CETES }}\right)=$ cantidad de pesos que se obtendrían al 
rendimiento esperado de la inversión en dólares consiste de la suma de dos factores: la tasa de rendimiento de los ВTE $\left(\mathrm{i}_{\mathrm{BTE}}\right.$ ) y la tasa de depreciación (o apreciación) esperada del peso frente al dólar (f). La prima por riesgo país $(\gamma)$ representa el rendimiento adicional que México debe ofrecer a los inversionistas por tratarse de un país en desarrollo, y se determina a partir de la situación de la economía mexicana y de la calificación de riesgo crediticio otorgada por las principales calificadoras de valores del mundo.

En ese contexto, la teoría tradicional de la política fiscal establece que una reforma hacendaria reduciría el déficit público, la colocación de CETES y la tasa de rendimiento de los mismos $\left(\mathrm{i}_{\mathrm{CETES}}\right)$. Esto, ceteris paribus, provocaría una desviación temporal respecto de la CAPI, donde la tasa de los CETES se ubicaría por debajo de la sumatoria de la tasa de los BTE, la tasa de ganancia (o pérdida) cambiaria esperada y la prima por riesgo país (esto es, $i_{\text {CETES }}<i_{\text {BTE }}+f+\gamma$ ). Esta situación, con el supuesto ceteris paribus, produciría salidas netas de capital y depreciaría la moneda.

La teoría del riesgo país, por su parte, postula que una reforma fiscal produciría una desviación de signo contrario en la CAPI. Concretamente, al recaudarse más y comprimirse la brecha entre los gastos y los ingresos públicos, no sólo se colocarían menos valores gubernamentales en el mercado financiero local sino que se fortalecerían los fundamentos de la economía y la confianza de los inversionistas. Ello provocaría que el ya mencionado descenso de la tasa de interés doméstica $\left(i_{\text {CETES }}\right)$ se viera acompañado por un decremento en la prima por riesgo país $(\gamma)$ y en la expectativa de depreciación de la moneda (f). En ese marco, si bien ambos lados de la ecuación 2 se verían alterados, el efecto neto favorecería la inversión en pesos (es decir, en el balance final: $i_{\text {CETES }}>i_{\text {BTE }}+f+\gamma$ ). ${ }^{21}$ De ese modo, en concordancia con la teoría que nos ocupa, habría entradas masivas de capital y el peso terminaría por apreciarse. La evidencia empírica de este trabajo sugiere que el efecto riesgo

cabo de un año por cada peso invertido en CETES a un año y $(\mathrm{F} / \mathrm{e})\left(1+\mathrm{i}_{\text {BTE }}\right)=$ cantidad de pesos que esperarían obtenerse al cabo de un año por cada peso invertido en BTE a un año, en la cual $\mathrm{F}=$ tipo de cambio anticipado dentro de un año. En segundo lugar, si México tiene que pagar una prima por riesgo país $\gamma$, entonces la condición de equilibrio en el mercado de bonos gubernamentales a plazo de un año es la siguiente: $\left(1+\mathrm{i}_{\text {СетеS }}\right)=(\mathrm{F} / \mathrm{e})\left(1+\mathrm{i}_{\text {BTE }}\right)+\gamma$. La ecuación que precede implica que: $\mathrm{i}_{\text {CFTES }}=(\mathrm{F} / \mathrm{e}-1)+(\mathrm{F} / \mathrm{e}) \mathrm{i}_{\mathrm{BTE}}+\gamma=(\mathrm{F}-\mathrm{e}) / \mathrm{e}+(\mathrm{F} / \mathrm{e}) \mathrm{i}_{\mathrm{BTE}}+\gamma=$ $(\mathrm{F} \sim \mathrm{e}) / \mathrm{e}+(\mathrm{F} / \mathrm{e}) \mathrm{i}_{\text {BTE }}+(\mathrm{e} / \mathrm{e}) \mathrm{i}_{\text {BTE }}-(\mathrm{e} / \mathrm{e}) \mathrm{i}_{\text {BTE }}+\gamma=(\mathrm{F} \sim \mathrm{e}) / \mathrm{e}+((\mathrm{F} \sim \mathrm{e}) / \mathrm{e}) \mathrm{i}_{\text {BTE }}+\mathrm{i}_{\text {BTE }}+\gamma$. De ese modo, si $((\mathrm{F} \sim \mathrm{e}) / \mathrm{e}) \mathrm{i}_{\mathrm{BTE}} \approx 0$ por ser el producto de dos fracciones, entonces: $\mathrm{i}_{\mathrm{CETES}} \approx \mathrm{i}_{\mathrm{BTE}}+(\mathrm{F} \sim \mathrm{e}) / \mathrm{e}+\gamma=$ $\mathrm{i}_{\text {BTE }}+\mathrm{f}+\gamma$, en la cual $\mathrm{F}=(\mathrm{F} \sim \mathrm{e}) / \mathrm{e}$.

21 Por supuesto, esta desviación respecto de la CAPI también sería temporal, dado que en el largo plazo se corregiría la desigualdad por la vía de los movimientos de capital. 
país domina al efecto tradicional de la política fiscal, ${ }^{22}$ toda vez que un menor déficit induce la apreciación del peso a pesar de la caída de la tasa de interés.

\section{Análisis empírico}

Para tratar de anticipar los principales efectos macroeconómicos de una reducción del déficit del sector público, se recurre a un parsimonioso modelo de autorregresión vectorial (modelo VAR) de seis variables: déficit público ( $\mathrm{DP}_{\mathrm{t}}$ ), base monetaria $\left(\mathrm{BM}_{\mathrm{t}}\right)$, la tasa de rendimiento nominal de los CETES a 28 días $\left(\mathrm{R}_{\mathrm{t}}\right)$, tipo de cambio $\left(\mathrm{TC}_{\mathrm{t}}\right)$, nivel de precios $\left(\mathrm{P}_{\mathrm{t}}\right)$, y producto global $\left(\mathrm{PG}_{\mathrm{t}}\right){ }^{23}$

La especificación del modelo VAR incluye las variables de interés en esta investigación y es consistente con trabajos previos referidos a la economía mexicana. Por ejemplo, Rogers y Wang (1994) y Cuevas (2002) desarrollan sendos modelos VAR para capturar la dinámica de la economía mexicana. El modelo de Rogers y Wang (1994) incorpora cinco variables: déficit fiscal, saldos monetarios reales, tipo de cambio real, producción y precios. Asimismo, estos autores señalan expresamente que la no inclusión de la tasa de interés obedece a que dicha variable estuvo regulada por el gobierno mexicano hasta abril de 1989; es decir, durante buena parte del periodo analizado por ellos (1977-1990). La investigación de Cuevas (2002), sin embargo, corresponde a un periodo (1990-2000) en el que las tasas de interés ya se encontraban determinadas por las fuerzas del mercado. De allí que este autor formule un modelo VAR de seis variables: las cinco variables ya referidas y la tasa de los CETES a 28 días.

Vale señalar, finalmente, que se sopesó la posibilidad de incluir otras variables en el modelo aquí desarrollado. Sin embargo, esta idea no prosperó debido a consideraciones relativas al tamaño de la muestra (132 observaciones para cada variable), al número de rezagos establecidos para cada variable en cada ecuación y a los grados de libertad requeridos para estimar eficientemente los parámetros del modelo.

La estimación de este modelo se realiza con base en información estadística mensual para cada una de las variables mencionadas en el periodo que va de enero de 1995 a diciembre de $2005 .{ }^{24}$ Es conveniente precisar que, al no existir datos

22 Es decir, la evidencia sugiere que el cambio en " $\gamma$ " $\mathrm{y}$ "f " supera en valor absoluto al cambio en " $i_{\text {CETES }}$ ". Formalmente, $\mid$ cambio en " $\gamma$ " + cambio en "f" $|>|$ cambio en " $i_{\text {CETES }}$ " $\mid$.

23 Para aquellos no versados en esta temática, se recomienda consultar el capítulo 2 del texto de Lutkepohl (1991), o el capítulo 14 de Patterson (2000).

24 Fuente: INEGI y Banco de México. 
mensuales sobre el PIB, se utiliza el Indicador Global de Actividad Económica (IGAE) como variable proxy. Para medir la oferta de dinero se emplea la base monetaria, en virtud de que el Banco de México ejerce un control más estrecho sobre esa variable que sobre cualquiera de los agregados monetarios (M1, M2, M3 y M4). Las otras variables incorporadas son: el déficit del sector público, ${ }^{25}$ el tipo de cambio fix del peso frente al dólar y el Índice Nacional de Precios al Consumidor (INPC), mismo que sirve para medir las variaciones en el nivel de precios. ${ }^{26}$

Con el objeto de garantizar la estacionariedad de las series, se realizaron dos tipos de pruebas para cada variable: Dickey-Fuller aumentadas (pruebas ADF) y Phillips-Perron (pruebas PP). Para especificar las ecuaciones de prueba, ${ }^{27}$ se siguió la metodología sugerida por Hamilton (1994:501), consistente en buscar aquella especificación que mejor refleje el comportamiento de los datos, tanto bajo la hipótesis nula, como bajo la hipótesis alternativa. Los resultados de dichas pruebas se presentan en el Cuadro 1.

Como puede constatarse en el cuadro que nos ocupa, a un nivel de significancia de $5 \%$ todas las variables son integradas de orden 1 (I(1)) en niveles y estacionarias (o I(0)) en primeras diferencias. En esa tesitura, el modelo VAR se estima en primeras diferencias y resulta, por ende, estacionario. La estructura dinámica del modelo se determinó con base en el Criterio de Información de Akaike, mismo que arrojó 12 rezagos para cada variable en cada ecuación como número óptimo.

La ecuación (3) representa al modelo de autorregresión vectorial en su forma estructural:

$$
\mathrm{y}_{\mathrm{t}}=\mathrm{C}+\mathrm{B}_{0} \mathrm{y}_{\mathrm{t}}+\mathrm{B}_{1} \mathrm{y}_{\mathrm{t}-1}+\mathrm{B}_{2} \mathrm{y}_{\mathrm{t}-2}+, \ldots \ldots,+\mathrm{B}_{12} \mathrm{y}_{\mathrm{t}-12}+\varepsilon_{\mathrm{t}}
$$

en la cual: $\mathrm{y}_{t}=\left[\mathrm{dp}_{\mathrm{t}}, \mathrm{bm}_{\mathrm{t}}, \mathrm{r}_{\mathrm{t}}, \mathrm{tc}_{\mathrm{t}}, \mathrm{p}_{\mathrm{t}}, \mathrm{pg}_{\mathrm{t}}\right]^{\prime}$ es un vector de variables macroeconómicas expresadas en primeras diferencias, ${ }^{28} \mathrm{C}$ es un vector de términos constantes, $\mathrm{B}_{\mathrm{i}}$ son matrices de coeficientes, donde $\mathrm{i}=0,1,2, \ldots, 12, \mathrm{y} \varepsilon_{\mathrm{t}}=\left[\varepsilon_{\mathrm{t}}^{\mathrm{dp}}, \varepsilon_{\mathrm{t}}^{\mathrm{bm}}, \varepsilon_{\mathrm{t}}^{\mathrm{r}}, \varepsilon_{\mathrm{t}}^{\mathrm{tc}}, \varepsilon_{\mathrm{t}}^{\mathrm{p}}, \varepsilon_{\mathrm{t}}^{\mathrm{pg}}\right]^{\prime} \mathrm{es}$

25 El sector público comprende al gobierno federal, al sector paraestatal y al sector extra presupuestal, excluyendo solamente a aquellas entidades cuya participación es marginal.

26 La información estadística utilizada se encuentra ajustada estacionalmente. Todos los datos, con excepción de los correspondientes al déficit público y a la tasa de rendimiento de los CETES, se expresan en logaritmos naturales.

27 Esto es, para decidir si éstas deberían incluir una constante, una constante y una tendencia determinística o ninguna de las dos cosas.

28 Simbólicamente, $d p_{t}=\left(D P_{t}-D P_{t-1}\right), b m_{t}=\left(B M_{t}-B M_{t-1}\right), r_{t}=\left(R_{t}-R_{t-1}\right)$, y así sucesivamente. 
Cuadro 1

Pruebas Dickey-Fuller aumentadas (ADF) y pruebas Phillips-Perron (PP). Ho: la variable en cuestión tiene una raíz unitaria

\begin{tabular}{ccccc}
\hline Variable & Especificación & Estadística ADF & Estadística PP & Orden de integración \\
\hline $\mathrm{DP}_{\mathrm{t}}$ & $\mathrm{C}$ & -0.39 & -0.85 & $\mathrm{I}(1)$ \\
$\mathrm{dp}_{\mathrm{t}}$ & Sin C ni TD & $-3.17^{* *}$ & $-17.36^{* *}$ & $\mathrm{I}(0)$ \\
$\mathrm{BM}_{\mathrm{t}}$ & $\mathrm{C} \mathrm{y} \mathrm{TD}$ & -1.45 & -3.39 & $\mathrm{I}(1)$ \\
$\mathrm{bm}_{\mathrm{t}}$ & $\mathrm{C}$ & $-3.38^{*}$ & $-14.78^{* *}$ & $\mathrm{I}(0)$ \\
$\mathrm{R}_{\mathrm{t}}$ & $\mathrm{C}$ & -2.77 & -2.33 & $\mathrm{I}(1)$ \\
$\mathrm{r}_{\mathrm{t}}$ & Sin C ni TD & $-9.04^{* *}$ & $-9.04^{* *}$ & $\mathrm{I}(0)$ \\
$\mathrm{TC}_{\mathrm{t}}$ & $\mathrm{C} \mathrm{y} \mathrm{TD}$ & -1.73 & -1.68 & $\mathrm{I}(1)$ \\
$\mathrm{tc}_{\mathrm{t}}$ & $\mathrm{C}$ & $-8.83^{* *}$ & $-9.20^{* *}$ & $\mathrm{I}(0)$ \\
$\mathrm{P}_{\mathrm{t}}$ & $\mathrm{C} \mathrm{TD}$ & -0.84 & -0.75 & $\mathrm{I}(1)$ \\
$\mathrm{p}_{\mathrm{t}}$ & $\mathrm{C}$ & $-4.77^{* *}$ & $-4.77^{* *}$ & $\mathrm{I}(0)$ \\
$\mathrm{PG}_{\mathrm{t}}$ & $\mathrm{Cy} \mathrm{TD}$ & -1.94 & -1.91 & $\mathrm{I}(1)$ \\
$\mathrm{pg}_{\mathrm{t}}$ & $\mathrm{C}$ & $-13.79^{* *}$ & $-13.79 * *$ & $\mathrm{I}(0)$ \\
\hline
\end{tabular}

Notas: las variables en minúsculas denotan las primeras diferencias de las variables en mayúsculas. Por ejemplo, $\mathrm{bm}_{\mathrm{t}}$ es la primera diferencia de $\mathrm{BM}_{\mathrm{t}} \mathrm{C}=$ constante y $\mathrm{TD}=$ tendencia determinística. Los asteriscos $*$ y $* *$ indican el rechazo de la hipótesis nula a un nivel de significancia de $5 \%$ y de $1 \%$, respectivamente. Tanto en las pruebas ADF como en las PP se utilizan los valores críticos de MacKinnon (1996). Dichos valores, por supuesto, varían en función de la especificación de la ecuación de prueba.

un vector de choques estructurales. Aquí se asume que los elementos de $\varepsilon_{\mathrm{t}}$ no están correlacionados y tienen un valor esperado igual a cero. ${ }^{29}$

Para identificar y estimar la ecuación (3) se recurre a la metodología desarrollada por Pesaran y Shin (1998). La metodología en cuestión está diseñada para eliminar la principal desventaja potencial de los modelos VAR recursivos, que consiste en la dependencia de la evidencia empírica obtenida con respecto del orden en que se coloquen las ecuaciones o variables del modelo. Utilizando el método referido, se estimaron cuatro funciones generalizadas de respuesta al impulso (FGRI), con sus respectivos intervalos de $95 \%$ de confianza. ${ }^{30}$ Dichas funciones permiten observar la respuesta dinámica de las tasas de interés, el tipo de cambio, los precios y el nivel de actividad económica frente a una reducción del déficit del sector público. ${ }^{31}$ Véase la Gráfica 9.

29 Vale decir, que los elementos $\varepsilon_{\mathrm{t}}^{\mathrm{dp}}, \varepsilon_{\mathrm{t}}^{\mathrm{bm}}, \varepsilon_{\mathrm{t}}^{\mathrm{r}}, \varepsilon_{\mathrm{t}}^{\mathrm{tc}}, \varepsilon_{\mathrm{t}}^{\mathrm{p}}$ y $\varepsilon_{\mathrm{t}}^{\mathrm{pg}}$ denotan choques fiscales, monetarios, financieros (o choques a las tasas de interés), cambiarios, inflacionarios y reales, respectivamente.

30 Se llaman funciones generalizadas porque, a diferencia de las funciones ordinarias que se obtienen mediante el método de Sims (1980), no dependen de la ordenación de las ecuaciones o variables del modelo var.

31 La reducción del déficit del sector público se simula de modo tal que su ocurrencia es al inicio del periodo, su duración es de un mes y su magnitud es de una desviación estándar. 

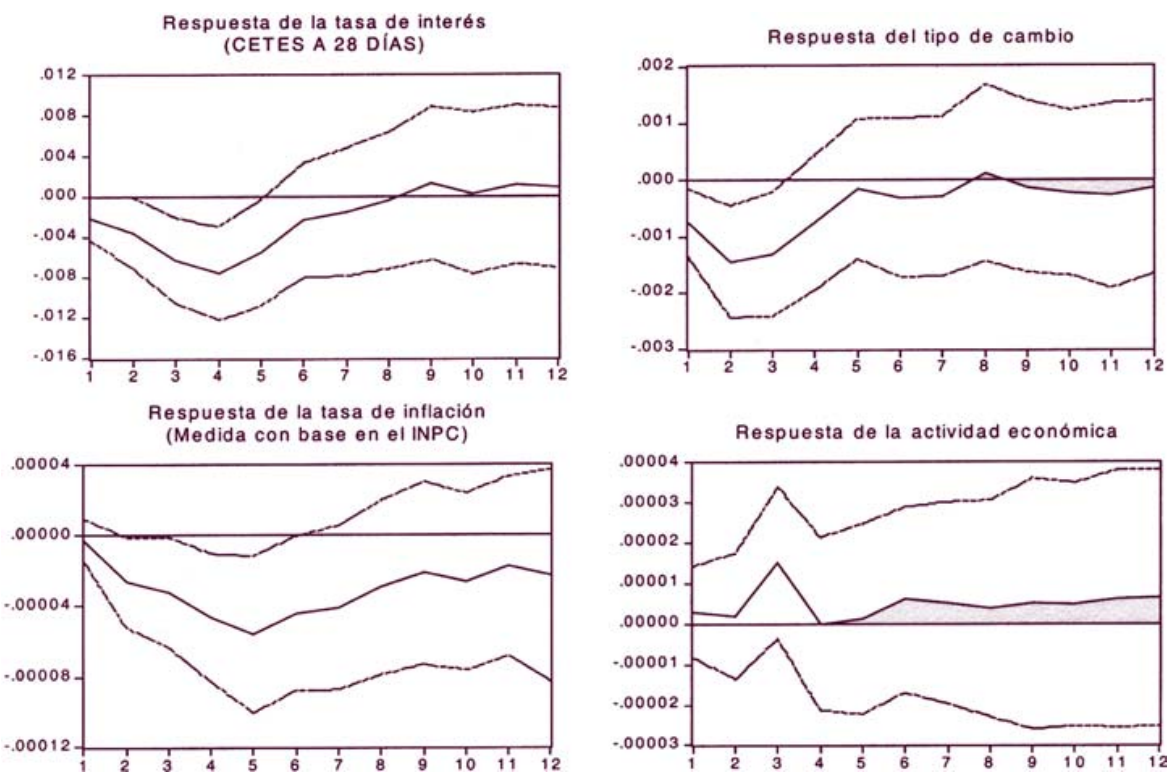

Gráfica 9. Efectos de una contracción del déficit fiscal.

Para que una función se considere estadísticamente significativa, es necesario que el intervalo de confianza respectivo excluya al cero en algún punto o intervalo dentro del horizonte de 12 meses. Como puede verse, una reducción del déficit ocasiona que la tasa de interés disminuya marcadamente por espacio de varios meses. El tipo de cambio, por su parte, se aprecia de inmediato y ese efecto tarda, aproximadamente, un trimestre en disiparse. Las presiones inflacionarias aminoran poco tiempo después de ocurrida la contracción fiscal y esa influencia estabilizadora se prolonga durante poco más de cinco meses. Finalmente, la función de respuesta del producto global no es estadísticamente significativa, dado que su intervalo de confianza incluye al cero en todo momento.

Con el fin de robustecer el análisis empírico, las funciones generalizadas de respuesta al impulso fueron reestimadas utilizando indicadores alternativos para la oferta de dinero, la tasa de interés y el nivel de precios. Los resultados de la Gráfica 10 provienen del empleo del M1 en sustitución de la base monetaria, de la tasa de los CETES a 91 días en lugar de a 28 días y del índice de inflación subyacente (que sirve para medir la tendencia de la inflación en el mediano plazo) en lugar del INPC.

El método de estimación empleado permite ortonormalizar los choques o innovaciones, de modo que la desviación estándar de cada uno de ellos es igual a uno. 

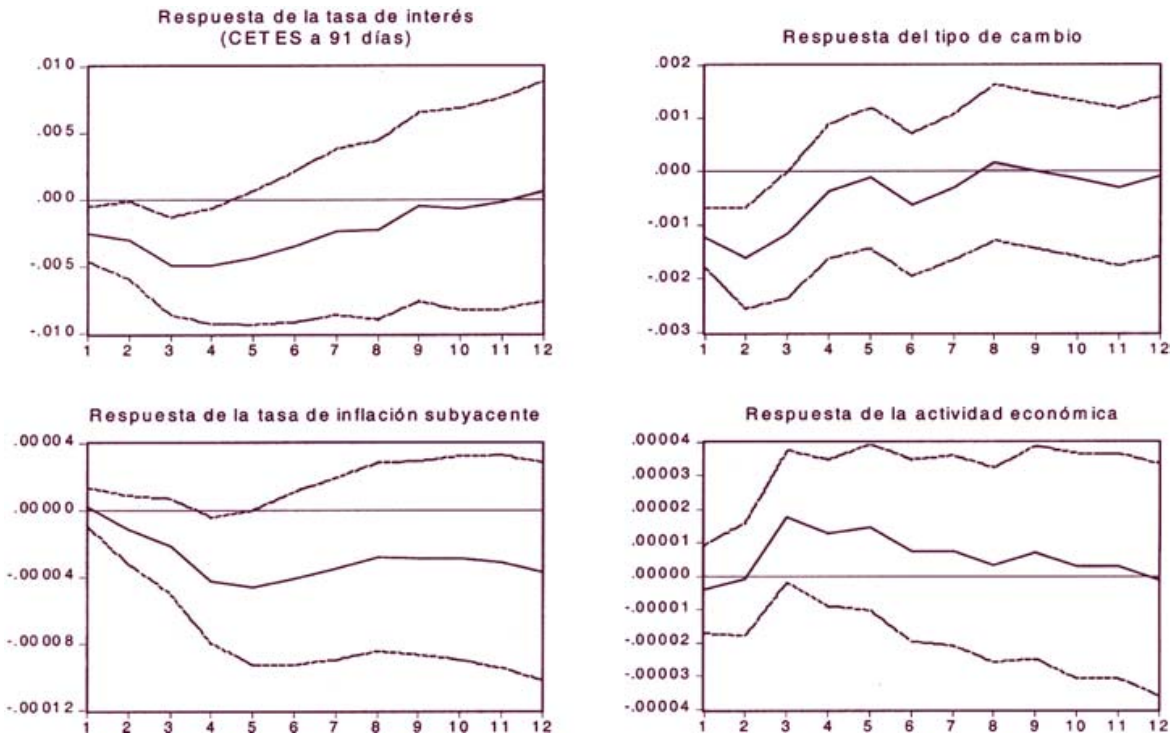

Gráfica 10. Efectos de una contracción del déficit fiscal con indicadores alternativos.

Por supuesto, estas variables también se expresaron en primeras diferencias para volverlas estacionarias.

Como puede observarse, los hallazgos son esencialmente los mismos. Quizá valdría la pena destacar que el descenso de la inflación es más tenue cuando se recurre a la tasa de inflación subyacente. Esto se explica en función de que dicho indicador es un subconjunto del INPC que excluye a los elementos volátiles.

En síntesis, el sucinto análisis empírico aquí realizado permite avalar a la teoría del riesgo país de la política fiscal, dado que el tipo de cambio se aprecia como resultado del menor déficit público. El dominio del efecto riesgo país sobre el efecto tradicional de la política fiscal es indicativo de la importancia creciente que los inversionistas institucionales (como casas de bolsa, fondos de inversión y bancos) otorgan a las calificaciones de riesgo crediticio de las diferentes naciones en las que invierten, sobre todo, si se trata de naciones en desarrollo.

\section{Lineamientos generales para una reforma fiscal en México}

Una RFI no sólo debe salvaguardar la solvencia del Estado mexicano, sino también promover la equidad, eficiencia, transparencia y flexibilidad del sistema impositivo. En ese contexto, la reforma del sistema fiscal mexicano debe tener como premisa la 
discusión, la negociación y la concreción de acuerdos respecto de los principios fundamentales que habrán de encauzar los esfuerzos de los poderes Ejecutivo y Legislativo en esa difícil y compleja tarea. Entre los principios más importantes que deben servir de guía y orientación permanentes a todos los actores involucrados en la realización de dicha reforma, se encuentran los siguientes:

1) La búsqueda de la equidad social e impositiva. Todo proyecto de reforma fiscal no sólo debe procurar la equidad, sino también la apariencia de equidad. Para cuidar tanto la esencia como la apariencia de la equidad se requiere de leyes, reglamentos y condiciones que garanticen un mismo tratamiento a todos los individuos o empresas que se encuentren en situaciones similares. Ello implica, por una parte, combatir la informalidad, la evasión y el incumplimiento de las obligaciones fiscales y, por la otra, procurar que el pago de impuestos refleje adecuadamente la capacidad de cada persona física y moral para contribuir al fisco. En consecuencia, la progresividad fiscal es un principio básico de equidad que debe preservarse y afinarse.

2) La mejora de la eficiencia. Además de la equidad, cualquier proyecto viable de reforma fiscal debe ocuparse de la eficiencia en la asignación de recursos escasos. Cuando los mercados funcionan adecuadamente, los precios constituyen señales hasta cierto punto confiables, no sólo para tomar decisiones en materia de asignación de recursos, sino para orientar la economía hacia un equilibrio general que maximice el bienestar. Para que un impuesto no distorsione demasiado las señales que el mercado envía tanto a productores como a consumidores y, por ende, para que no represente un obstáculo severo para el crecimiento económico y la generación de empleos, éste debe diseñarse de modo que no desincentive significativamente el trabajo, el ahorro, la inversión y la asunción de riesgos empresariales. Los impuestos indirectos (como el IVA) son una de las rutas para mejorar la eficiencia tributaria, puesto que distorsionan los patrones de producción y de consumo en menor medida que los impuestos directos (como el ISR). Sin embargo, habría que analizar la factibilidad técnica y social de privilegiar los impuestos al consumo por encima de los impuestos al ingreso, dado que existen por lo menos dos objeciones para ello. La primera es que, como se muestra en la Gráfica 5, la carga fiscal de México es considerablemente baja en el renglón de impuesto sobre la renta. La segunda objeción es que los impuestos al consumo pueden afectar más precisamente a los que menos tienen e ir en detrimento de la equidad impositiva, misma que no debe subordinarse frente a la necesidad de mejorar la eficiencia. 
No obstante lo anterior, existe la posibilidad de formular esquemas impositivos que corrijan el funcionamiento deficiente del mercado y permitan recaudar más sin afectar demasiado la equidad. Por ejemplo, los impuestos al tabaco y a las bebidas alcohólicas constituyen no sólo alternativas de ingresos fiscales adicionales, sino mecanismos para corregir las externalidades negativas derivadas del consumo excesivo de los productos referidos. ${ }^{32}$

3) La transparencia fiscal. Este concepto está directamente relacionado con la necesidad de que el sistema impositivo sea fácilmente comprensible para los contribuyentes, de que resulte sencillo determinar cuánto y cómo debe pagar cada persona física o moral y de que se conozcan claramente los beneficios derivados del cumplimiento de las obligaciones fiscales.$^{33}$ Condiciones sine qua non para que un sistema fiscal sea transparente son la simplicidad del mismo, el establecimiento de reglas claras para el pago de impuestos, el diseño de procedimientos expeditos para la realización de trámites fiscales y la rendición permanente de cuentas respecto de los avances y resultados de la gestión fiscal de los diferentes órdenes de gobierno. Por el lado del manejo de las erogaciones públicas, una acción de transparencia muy necesaria consiste en que los pasivos extraoficiales o implícitos del sector público sean reconocidos como deuda pública, que se valore adecuadamente la naturaleza real o contingente de dichos pasivos y que se tomen más en cuenta dentro del proceso de saneamiento de las finanzas públicas. Ello contribuirá a transparentar y mejorar el manejo y control del gasto público, a abaratar el servicio de los pasivos implícitos — que incorporan una prima de riesgo por no formar parte de la deuda pública - y a garantizar que el esfuerzo de consolidación fiscal del gobierno mexicano rinda frutos permanentes.

32 Cuando una industria, como la tabacalera o la alcoholera, ocasiona costos a la sociedad sin resarcirla adecuadamente por éstos, entonces se está en presencia de una externalidad negativa. Ese fenómeno puede atenuarse mediante la fijación o el incremento de determinados impuestos, como los que gravan la producción de cigarros y de alcohol. Con medidas de esa naturaleza se desalienta el consumo excesivo de productos potencialmente nocivos para la salud, se compensa en alguna medida a la sociedad y se financia al sistema de salud pública, el cual destina elevados recursos al tratamiento del tabaquismo y del alcoholismo, así como a la atención y cura de enfermedades asociadas con tales adicciones.

33 El ISR es un buen ejemplo de impuesto transparente, porque resulta simple determinar cuánto debe pagar cada individuo o cada empresa. Por otra parte, para determinar los beneficios provenientes del pago de este impuesto, o de cualquier otro, es preciso cuidar la calidad, integridad y grado de detalle de la información relativa a la formulación y ejercicio del presupuesto. El IVA, contrariamente, es un impuesto poco transparente, puesto que resulta más complicado calcular cuál es la contribución de cada consumidor al fisco. 
4) La flexibilidad de la estructura fiscal. La política fiscal y la estructura del sistema de impuestos deben contribuir, de manera conjunta, a amortiguar los efectos de perturbaciones exógenas - como descensos pronunciados en la actividad económica estadounidense o incrementos significativos en las tasas internacionales de interés - sobre la economía nacional. Ciertamente, la creación del Fondo de Estabilización Petrolera ha contribuido a mejorar el funcionamiento de los estabilizadores fiscales automáticos, pero hace falta crear mecanismos expeditos para enfrentar recesiones severas, así como afinar los canales de comunicación y negociación con el Congreso para poder acordar, aprobar e instrumentar modificaciones en el ámbito hacendario de manera más eficiente y oportuna.

5) La elevación de la calidad del gasto gubernamental. El incremento de la productividad y la competitividad internacional del país, así como la mejora en los niveles de bienestar de la población, demandan la canalización de suficientes recursos públicos no sólo a la generación de capital físico y al desarrollo de nuevas tecnologías, sino a la protección y acumulación de capital humano y al desarrollo regional equilibrado del país. El ordenamiento de las finanzas públicas durante los años recientes ha menoscabado tanto la inversión pública como el gasto social. De allí que deba reimpulsarse la inversión pública en infraestructura, articulándola con políticas sectoriales de aliento a las inversiones privadas. También debe acrecentarse el gasto social, sobre todo en renglones con alto impacto redistributivo, como salud, educación, vivienda, desarrollo rural integral y combate a la pobreza. En contrapartida, el gasto corriente —en particular, el gasto en servicios personalesdebe reducirse, y ejercerse de manera más eficiente y responsable.

6) La búsqueda de la solvencia fiscal. Cualquier reforma fiscal que se emprenda debe poner a salvo la solvencia del Estado y la viabilidad de la política fiscal en el largo plazo. La solvencia gubernamental requiere que el valor presente del superávit primario esperado sea igual o mayor que el denominado Saldo Histórico de los Requerimientos Financieros del Sector Público (SHRFSP). ${ }^{34}$ En ese contexto, una condición necesaria para salvaguardar la solvencia fiscal es la elevación de la recaudación como porcentaje del PIB, buscando que México se aproxime gradualmente al promedio de la OCDE. Ello solamente podría lograrse ampliando la base gravable, eliminando exenciones poco justificadas y combatiendo frontalmente la informali-

34 El superávit primario es igual a la diferencia entre los ingresos públicos y el gasto público sin considerar las erogaciones destinadas al servicio de la deuda pública total. El SHRFSP, por otra parte, es un concepto que se definió previamente. 
dad, para que de ese modo más sectores, empresas e individuos aporten recursos al fisco. Una condición suficiente para la solvencia fiscal sería, por otra parte, que el sendero proyectado del SHRFSP sea sustentable, es decir, que sea compatible con la futura capacidad de pago del Estado.

\section{Conclusiones}

La historia reciente del país demuestra que la salud de las finanzas públicas es una condición necesaria (aunque insuficiente) para conjuntar estabilidad macroeconómica, crecimiento sostenido e inserción eficiente de la economía en las corrientes internacionales de comercio e inversión. Como se ha visto, a partir de 1999, gracias al esfuerzo de saneamiento financiero desplegado por el Estado, tanto el déficit público como los RFSP han venido reduciendo su participación en el PIB. No obstante que eso ha permitido reducir la deuda pública neta total —medida en función del PIB-, el SHRFSP se mantiene en niveles relativamente elevados. Ese fenómeno, aunado a la insuficiente recaudación fiscal del país, la acentuada dependencia respecto de los ingresos petroleros y la desmesurada acumulación de obligaciones contingentes, compromete seriamente la solvencia del sector público en el mediano y largo plazos.

De allí la necesidad y pertinencia de una RFI que fortalezca los ingresos públicos y permita conciliar la disciplina fiscal, no sólo con la corrección de los rezagos sociales acumulados, sino con la expansión de la inversión pública en infraestructura. Lo anterior en virtud de que, además de preservar la estabilidad macroeconómica, es necesario mejorar los niveles de bienestar de la población y acrecentar la competitividad internacional de las empresas mexicanas. El breve análisis empírico aquí realizado sugiere que una reducción temporal del déficit fiscal haría bajar las tasas de interés, disminuiría la tasa de inflación y apreciaría la moneda doméstica en el corto plazo. Sin embargo, es necesario generar evidencia empírica robusta respecto de las repercusiones económicas de largo plazo que tendría una RFI en nuestro país.

Como se ha insistido, todo proyecto de reforma fiscal debe encontrar un equilibrio razonable entre la búsqueda de la solvencia financiera y la necesidad de construir un régimen tributario que sea equitativo, eficiente, transparente y flexible. El imperativo de encontrar equilibrios adecuados entre los diferentes atributos de un buen sistema hacendario obedece a que el cobro de mayores impuestos puede ir en detrimento de la eficiencia; o bien, la consecución de la equidad social puede derivar en un sistema impositivo más complejo y menos transparente y flexible. La existencia de este tipo de relaciones de intercambio subraya la conveniencia de 
discutir y acordar de antemano las prioridades, principios y valores que habrán de orientar una eventual reforma fiscal. Un buen punto de partida sería colocar a la solvencia, equidad y eficiencia fiscales como los tres ejes rectores de la reforma. En segundo lugar, habría que cuidar el carácter integral de la misma, pues ésta debe ocuparse no sólo de la recaudación de impuestos sino, también, de las otras tres vertientes del andamiaje hacendario: el gasto y el endeudamiento públicos y el sistema de fiscalización, vigilancia y regulación de cuanto erogue, ingrese y pida prestado el Estado mexicano. Hasta ahora, la debilidad de los ingresos ha obligado a sacrificar el gasto social y la inversión pública en aras de la disciplina fiscal. De allí que el saneamiento de las finanzas y la estabilidad macroeconómica alcanzada no se hayan traducido en mayor crecimiento económico ni hayan permitido avances sustanciales en renglones sensibles como salud, educación, vivienda y combate a la pobreza.

\section{Bibliografía}

Alesina, A. y A. Drazen, "Why are stabilizations delayed?", en American Economic Review, vol. 81 (diciembre), 1991, pp. 1170-1188.

Ball, L., y G. Mankiw, "What do budget deficits do?", en Budget deficits and debt: Issues and options, Federal Reserve Bank of Kansas City, 1995.

Barro, R., "Are government bonds net wealth?", en Journal of Political Economy, núm. 82, 1974, pp. 1095-1117.

Bayoumi, T. y P. Masson, "Liability-creating versus non-liability-creating fiscal stabilization policies: Ricardian equivalence, fiscal stabilization and EMU", en IMF Working Papers, núm. 112, Washington, Fondo Monetario Internacional, 1998.

Blanchard, O., "Output, the stock market, and interest rates", en American Economic Review, núm. 71 (1), 1981, pp. 132-143.

, "Current and anticipated deficits, interest rates and economic activity", en European Economic Review, núm. 25(1), 1984,pp. 7-27.

_ "Debt, deficits and finite horizons", en Journal of Political Economy, núm. 93 (2), 1985, pp. 223-47.

Blanchard, O. y R. Dornbusch, "U.S. deficits, the dollar and Europe", en Banca Nazionale del Lavoro Quarterly Review, núm. 148, 1984, pp. 89-113.

Botman, D. y M. Kumar, "Fundamental determinants of the effects of fiscal policy", en IMF Working Papers, núm. 76, Washington, Fondo Monetario Internacional, 2006.

Branson, W., A. Fraga y R. Johnson, "Expected fiscal policy and the recession of 1982", en International Finance Discussion Paper, núm. 272, Board of Governors of the Federal Reserve System, Washington, Federal Reserve System, 1985.

Calvo, G. y C. Végh, "Inflation stabilization and BOP crises in developing countries", en John Taylor y Michael Woodford (editores), Handbook of Macroeconomics, , Volume C, Amsterdam, Holanda, 1999.

Cuevas Ahumada, V., "Efectos del déficit fiscal en la economía mexicana: un análisis empírico", en Comercio Exterior, vol. 52, núm. 12, 2002, pp. 1109-1123.

Dómenech, R., D. Taguas, y J. Varela, "The effects of budget deficit on national savings in the OECD", en Economic Letters, vol. 69 (3), 2000, pp. 377-383.

Dornbusch, R., "Flexible exchange rates and excess capital mobility", en Brookings 
Papers on Economic Activity, núm. 1, 1986, pp. 209-26.

Evans, P., "Do budget deficits raise nominal interest rates? Evidence from six Countries", en Journal of Monetary Economics, núm. 20 (2), 1987a, pp. 281-300.

, "Interest rates and expected future budget deficits in the United States", en Journal of Political Economy, núm. 95 (1), 1987b, pp. 34-58.

,"Do large deficits produce high interest rates?", en American Economic Review, núm. 75 (1), 1985, pp. 68-85.

Eichengreen, B., Hacia una nueva arquitectura financiera internacional: propuesta después de la crisis asiática, Oxford University Press, 2000.

Feldstein, M., "Can an increased budget deficit be contractionary?", en Working paper 1434, Cambridge, Mass., National Bureau of Economic Research (agosto), 1984.

Flemming, M., "Financial market implications of the federal debt paydown", en Brookings Papers on Economic Activity, núm. 2, 2000, pp. 221-251.

Frenkel, J. y A. Razin, "The Mundell-Fleming model: A quarter-century later", en IMF Staff Papers (diciembre), 1987.

Giorgioni, G. y K. Holden, "Does the Ricardian equivalence proposition hold in less developed countries?", en International Review of Applied Economics, Vol. 17, núm. 2, 2003, pp. 209-221.

Hamilton, J., Time series analysis, Princeton University Press, 1994.

Lutkepohl, H., Introduction to multiple time series analysis, Springer-Verlag Berlin, Heidelberg, Alemania, 1991.

De Mello, L., P. Kongsrud y R. Price, "Saving behaviour and the effectiveness of fiscal policy", en $O E C D E C O / W K P$, núm. 397, Organización para la Cooperación y el Desarrollo Económicos, 2004.

McDermott, J. y R. Wescott, "An empirical analysis of fiscal adjustments", en IMF Staff
Papers, vol. 43, Núm. 4, Washington, Fondo Monetario Internacional, 1996.

Patterson, K., An introduction to applied econometrics, Macmillan Press, Londres, 2000.

Perotti, R., "Fiscal policy in good times and bad", en Quarterly Journal of Economics, septiembre de 1999, pp. 1399-1436.

- "Estimating the effects of fiscal policy in OECD countries", en ECB Working Paper, núm. 168, Francfort, Banco Central Europeo, 2002.

Pesaran, M. y Y. Shin, "Impulse response analysis in linear multivariate models", en Economic Letters, núm. 58, 1998, pp. 165-193.

Plosser, C., "Government financing decisions and asset returns", en Journal of Monetary Economics, núm. 9 (3), 1982, pp. 325-52.

-, "Fiscal policy and term structure", en Journal of Monetary Economics, núm. 20 (2), 1987, pp. 343-367.

Reinhart, V. y B. Sack, "The economic consequences of disappearing government debt", en Brookings Papers on Economic Activity, núm. 2, 2000, pp. 163-220.

Rivera-Batiz, F. y L. Rivera-Batiz, International finance and open economy macroeconomics, Prentice-Hall, Nueva Jersey, 1994.

Rogers, J. y P. Wang, "Output, inflation, and stabilization in a small open economy: Evidence from Mexico", en Journal of Development Economics, vol. 46, 1994, pp. 271-293.

Sargent, T. y N. Wallace, "Some unpleasant monetary arithmetic", en Federal Reserve Bank of Minneapolis Quarterly Review, Otoño, Minneapolis, 1981.

Stiglitz, J., "On the relevance or irrelevance of public financial policy", en J. Arrow y M. Boskin (editores), Economics of Public Debt, New York, Macmillan Press, 1988, pp. 41-76.

Sutherland, A., "Fiscal crises and aggregate demand: can high public debt reverse the effects of fiscal policy?", en Journal of Public Economics, núm. 65, 1997, pp. 147-162. 